\title{
An electrodynamics model for Data Interpretation and Numerical Analysis of ionospheric Missions and Observations (DINAMO)
}

\author{
Samuel A. Shidler ${ }^{1,2^{*}}$ and Fabiano S. Rodrigues ${ }^{1}$
}

\begin{abstract}
We introduce a new numerical model developed to assist with Data Interpretation and Numerical Analysis of ionospheric Missions and Observations (DINAMO). DINAMO derives the ionospheric electrostatic potential at low- and mid-latitudes from a two-dimensional dynamo equation and user-specified inputs for the state of the ionosphere and thermosphere (I-T) system. The potential is used to specify the electric fields and associated F-region $\mathbf{E} \times \mathbf{B}$ plasma drifts. Most of the model was written in Python to facilitate the setup of numerical experiments and to engage students in numerical modeling applied to space sciences. Here, we illustrate applications and results of DINAMO in two different analyses. First, DINAMO is used to assess the ability of widely used I-T climatological models (IRI-2016, NRLMSISE-00, and HWM14), when used as drivers, to produce a realistic representation of the low-latitude electrodynamics. In order to evaluate the results, model $\mathbf{E} \times \mathbf{B}$ drifts are compared with observed climatology of the drifts derived from long-term observations made by the Jicamarca incoherent scatter radar. We found that the climatological I-T models are able to drive many of the features of the plasma drifts including the diurnal, seasonal, altitudinal and solar cycle variability. We also identified discrepancies between modeled and observed drifts under certain conditions. This is, in particular, the case of vertical equatorial plasma drifts during low solar flux conditions, which were attributed to a poor specification of the E-region neutral wind dynamo. DINAMO is then used to quantify the impact of meridional currents on the morphology of F-region zonal plasma drifts. Analytic representations of the equatorial drifts are commonly used to interpret observations. These representations, however, commonly ignore contributions from meridional currents. Using DINAMO we show that that these currents can modify zonal plasma drifts by up to $\sim 16 \mathrm{~m} / \mathrm{s}$ in the bottom-side post-sunset F-region, and up to $\sim 10 \mathrm{~m} / \mathrm{s}$ between 0700 and $1000 \mathrm{LT}$ for altitudes above $500 \mathrm{~km}$. Finally, DINAMO results show the relationship between the pre-reversal enhancement (PRE) of the vertical drifts and the vertical shear in the zonal plasma drifts with implications for equatorial spread $\mathrm{F}$.
\end{abstract}

Keywords: Ionosphere, Plasma drifts, Modeling, Equatorial, Currents, Electric fields, Potential

\section{Introduction}

It is well-known that equatorial $F$-region plasma drifts play an important role in fundamental ionospheric

\footnotetext{
*Correspondence: sam.shidler24@gmail.com

1 William B. Hanson Center for Space Sciences, The University of Texas

at Dallas, 800 W Campbell Rd, Richardson, TX 75080, USA

Full list of author information is available at the end of the article
}

processes and space weather phenomena. For instance, the equatorial upward vertical drifts contribute to the distribution and structure of ion composition and temperatures of the ionospheric plasma at low latitudes (e.g., Balan et al. 1997; Huang et al. 2016; Hysell et al. 2015; Schunk and Nagy 2009). Additionally, the PRE of the vertical drifts in the evening sector can set up conditions that are favorable for the development of equatorial spread-F 
(ESF) ionospheric irregularities (Abdu et al. 1983; Fejer et al. 1999; Huang 2018; Huang and Hairston 2015; Smith et al. 2015; Sultan 1996) which can affect signals used for communication, navigation and remote sensing systems (Basu et al. 1988; Carrano et al. 2012; Kintner et al. 2007). Other studies have pointed out the role of zonal plasma drifts in the stability of the evening equatorial $F$-region (Aveiro and Hysell 2010; Hysell and Kudeki 2004; Kudeki and Bhattacharyya 1999; Kudeki et al. 2007).

Past modeling studies of the plasma drifts (e.g., Eccles 1998; Eccles et al. 2015; Haerendel et al. 1992; Heelis et al. 1974; Huba et al. 2010; Maute et al. 2012) have demonstrated that the main features of the observed $F$-region plasma drifts are driven by the $E$ - and $F$-region neutral wind dynamo. Further analyses indicated that gradients in the gravity-driven current system near dawn and dusk produce polarization electric fields that modify the plasma drifts by $5-15 \mathrm{~m} / \mathrm{s}$ (e.g., Eccles 2004). In Heelis et al. (1974), the electric potential is found on a thin conducting shell at the upper boundary of the E-region using height-integrated horizontal currents with communication from the F-layer provided by field-aligned currents. The more recent studies (e.g., Eccles 1998; Eccles et al. 2015; Haerendel et al. 1992; Huba et al. 2010) have successfully used a field line integrated, two-dimensional model to describe the electrodynamics of the low-latitude ionosphere. Within this framework, three-dimensional conductivities and drivers (i.e., neutral winds and gravity) are integrated along magnetic field lines effectively "collapsing" the three-dimensional electrodynamics onto a two-dimensional plane located at the magnetic equator (Haerendel et al. 1992). Expanding the field line integrated current continuity equations results in a twodimensional partial differential equation for the electrostatic potential that can be used to specify electric fields perpendicular to the background magnetic field.

Recent launches of the Ionospheric Connections Explorer (ICON) (Immel et al. 2018) and FORMOsa SATellite-7/Constellation Observing System for Meteorology Ionosphere and Climate (FORMOSAT-7/COSMIC-2) (Anthes and Schreiner 2019) will provide the space physics community with a comprehensive new set of thermosphere-ionosphere measurements in an effort to advance our understanding of low-latitude ionospheric variability and space weather. Included in the suite of instruments onboard these satellites are the Ion Velocity Meters (IVM) which are capable of providing in situ measurements of plasma drifts (Heelis et al. 2017). The University of Texas at Dallas (UTD) has been responsible for the design and development of IVM and has also made advances toward the miniaturization and use of this instrument in cubesat missions (e.g., Crowley et al. 2016; Spann et al. 2017). Therefore, the importance of
$F$-region drifts to fundamental and applied studies of the low-latitude ionosphere and the increase in the number of distributed observations motivated us in the direction of new modeling efforts at UTD.

Here, we introduce a new electrodynamics model that was created to assist with efforts related to Data Interpretation and Numerical Analysis of ionospheric Missions and Observations (DINAMO). DINAMO solves the ionospheric dynamo equation using user-specified representations of the ionospheric and thermospheric parameters at middle and low latitudes. More specifically, DINAMO determines the polarization electric fields that are setup in response to the neutral wind and gravitational dynamos. Of particular importance is the fact that the model was written in Python, with the exception of the potential solver, to facilitate changes, tests, and the engagement of students with numerical modeling in space sciences.

While the model was developed to assist the analysis and interpretation of ionospheric observations, here we focus on describing its development and illustrating some of its results through two distinct applications. In the first application, we employ DINAMO to assess the ability of using current empirical models (IRI-2016, HWM14, NRLMSISE-00) as inputs to drive realistic representations of the low-latitude electrodynamics. More specifically, we evaluate the ability of these widely used models to produce plasma drifts that are compatible with observations made by the Jicamarca incoherent scatter radar (ISR) (Kudeki and Bhattacharyya 1999). In the second application, we use DINAMO to evaluate the contribution of the integrated vertical current $\left(J_{L}\right)$ to the morphology of the equatorial $F$-region zonal drifts. Previous studies invoked a simple analytic expression describing the zonal drifts to interpret observations or to model the drifts (Chau and Woodman 2004; Eccles 1998; Haerendel et al. 1992; Richmond et al. 2015; Rodrigues et al. 2012; Shidler et al. 2019). With the exception of Haerendel et al. (1992), which considered a few different values of $J_{L}$, these studies neglected the contribution of the vertical integrated current to the morphology of the zonal drifts. Analyses of the DINAMO outputs allow us to quantify the contribution of $J_{L}$ to the equatorial zonal drifts.

The presentation is organized as follows: In Sect. 2, we provide information about the development of DINAMO and the climatological models of the I-T system used as drivers. In Sect. 3, we present DINAMO model results for different seasons and solar flux conditions. We compare these results with mean plasma drifts measured by the Jicamarca ISR. The main goal here is to determine to what extent current climatological models of the thermosphere-ionosphere system can drive low-latitude electrodynamics that are in agreement with the observations. 
Then, we use DINAMO model results to evaluate the integrated vertical current $\left(J_{L}\right)$. The goal is to quantify the contribution of $J_{L}$ to the morphology of the zonal drifts. Finally, Sect. 4 summarizes our main findings and provides concluding remarks.

\section{Model description: DINAMO}

Here, we describe a new ionospheric electrodynamics model that has been developed to assist with Data Interpretation and Numerical Analyses of ionospheric Missions and Observations (DINAMO). DINAMO is a numerical model that solves the ionospheric dynamo equation for the low-latitude ionospheric electrostatic potential at the magnetic equator given user inputs for the state of the I-T system. The electric potential allows for the specification of electric fields perpendicular to the background magnetic field $(\mathbf{E})$ and the associated vertical and zonal $\mathbf{E} \times \mathbf{B}$ plasma drifts.

Most of the DINAMO code was written in Python. This facilitates implementations of numerical experiments and modifications of input parameters. The choice of Python also facilitates the engagement of students in numerical modeling and space sciences. Of specific relevance to this report is Pyglow (https://github.com/timdu ly4/pyglow). Pyglow is a community-developed Python module that wraps several widely used empirical models of the I-T system into one easy-to-use package. Pyglow is particularly useful in the present study where one of the goals is to evaluate the electrodynamics produced by DINAMO given inputs provided by current climatological models of I-T system.

The numerical method for solving the dynamo equation is provided by MUDPACK, a collection of FORTRAN subroutines that efficiently solves elliptic partial differential equations (Adams 1989). This software is the same used by the National Center for Atmospheric Research (NCAR) in their Thermosphere-IonosphereElectrodynamics General Circulation Model (TIE-GCM) for the solution scheme of the electric potential (Maute 2018).

Figure 1 provides an overview of the DINAMO pipeline. Model runs start by tracing out the magnetic field

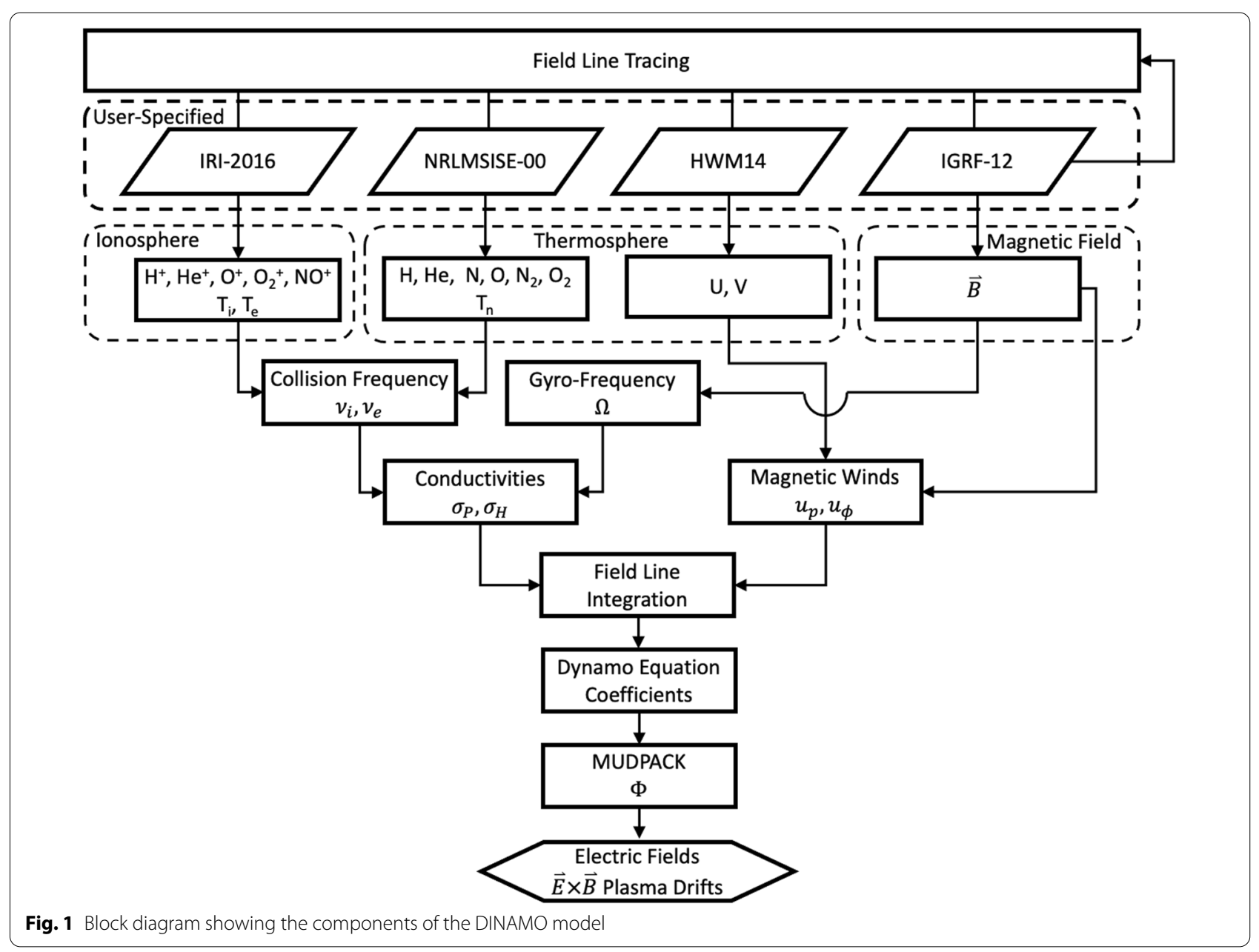


lines using a user-specified model for the background magnetic field. DINAMO then gets the physical parameters of the ionosphere, thermosphere, and magnetic field for each point along the field line again using user-specified models. The conductivities and magnetic meridional and zonal winds are calculated from the physical parameters and are then used to numerically compute the twodimensional field line integrated quantities. Next, the coefficients of the ionospheric dynamo equation are computed and fed into MUDPACK which numerically solves for the electrostatic potential at the magnetic equator. Finally, the electric potential is used to determine the electric fields and associated $\mathbf{E} \times \mathbf{B}$ plasma drifts. The following subsections provide more details about the model.

\subsection{The dynamo equation}

The prevailing starting point for modeling electric fields within the low-latitude ionosphere is the current continuity equation. These electric fields develop to ensure that the net current density is divergence-free $(\nabla \cdot \mathbf{j}=0)$ (Eccles 2004; Eccles et al. 2015; Haerendel et al. 1992; Heelis et al. 1974; Huba et al. 2010). In this work, the modeled electric fields are setup in response to neutral wind and gravity driven current systems perpendicular to the magnetic field. Here, we have chosen to neglect currents driven by pressure-gradients force as Eccles (2004) showed that they do not have a significant effect on the equatorial plasma drifts. We point out, however, that pressure-gradient currents can be important when interpreting high accuracy satellite magnetic observations (Alken 2016; Alken et al. 2011).

A natural coordinate system for analyzing the behavior of a magnetized plasma is the dipole coordinates system $(q, p, \phi)$. The coordinate $q$ and associated unit vector $\mathbf{e}_{q}$ is parallel to Earth's magnetic field $\mathbf{B}$. The coordinate $p$ and unit vector $\mathbf{e}_{p}$ is perpendicular to $\mathbf{B}$ and pointed poleward and is contained within the magnetic meridian. Finally, $\phi$ points in the magnetic zonal direction $\left(\mathbf{e}_{\phi}=\mathbf{e}_{q} \times \mathbf{e}_{p}\right)$. In this coordinate system, the currents perpendicular to $\mathbf{B}$ are given by:

$$
\begin{aligned}
& j_{p}=\sigma_{P}\left(E_{p}+B u_{\phi}\right)-\sigma_{H}\left(E_{\phi}-B u_{p}\right)+\sum_{i} \sigma_{P i} \frac{m_{i} g_{p}}{e} \\
& j_{\phi}=\sigma_{P}\left(E_{\phi}-B u_{p}\right)+\sigma_{H}\left(E_{p}+B u_{\phi}\right)-\sum_{i} \sigma_{H i} \frac{m_{i} g_{p}}{e},
\end{aligned}
$$

where

- $\sigma_{P}$ - Pedersen conductivity $[\mathrm{mho} / \mathrm{m}]$

- $\sigma_{H}$ - Hall conductivity $[\mathrm{mho} / \mathrm{m}]$

- $E_{p}$ - Meridional electric field $[\mathrm{V} / \mathrm{m}]$
- $E_{\phi}$ - Zonal electric field $[\mathrm{V} / \mathrm{m}]$

- $u_{p}$ - Magnetic meridional neutral wind $[\mathrm{m} / \mathrm{s}]$

- $u_{\phi}$ - Magnetic zonal neutral wind $[\mathrm{m} / \mathrm{s}]$

- $B$ - Magnetic field strength [T]

- $m_{i}$ - Ion mass $[\mathrm{kg}]$

- $e$ - Electron charge [C]

- $g_{p}$ - Meridional gravitational acceleration component $\left[\mathrm{m} / \mathrm{s}^{2}\right]$

We do not specify the parallel current $\left(j_{q}\right)$, but as we will show, our model results are independent of this quantity.

In this work, the electrodynamics of the low-latitude ionosphere are described using the two-dimensional field line integrated model derived by Haerendel et al. (1992), and successfully used in various previous studies (e.g., Chau and Woodman 2004; Eccles 1998, 2004; Eccles et al. 2015; Huba et al. 2010; Richmond et al. 2015; Rodrigues et al. 2012; Shidler and Rodrigues 2021) to advance the understanding of the low-latitude ionospheric electrodynamics. Within this framework, three-dimensional quantities are integrated along magnetic field lines starting at the base of the ionosphere where parallel currents are expected to vanish. The resulting two-dimensional quantities are then assigned to points at the magnetic dip equator defined by the location of the apex heights of the field lines. The two coordinates used in this plane are the McIlwain parameter $L=R / R_{E}$ and $\varphi$, where $R$ is the distance from the center of the Earth to the apex height of the field line, $R_{E}$ is the radius of the earth, and $\varphi$ measures the angle in the magnetic zonal direction.

Therefore, a two-dimensional current continuity equation is found by integrating the three-dimensional current continuity equation along magnetic field lines (Wohlwend 2008):

$$
\begin{aligned}
\nabla \cdot \mathbf{J}= & \int \nabla \cdot \mathbf{j} h_{q} d q=\int \frac{1}{h_{q} h_{p} h_{\phi}}\left[\frac{\partial}{\partial q}\left(j_{q} h_{p} h_{\phi}\right)+\frac{\partial}{\partial \phi}\left(j_{\phi} h_{q} h_{p}\right)\right. \\
& \left.+\frac{\partial}{\partial p}\left(j_{p} h_{\phi} h_{q}\right)\right] h_{q} d q,
\end{aligned}
$$

where $h_{q}, h_{p}$, and $h_{\phi}$ are geometric scale factors. The limits of integration start and end at the bases (northern and southern hemispheres) of the ionosphere where parallel currents are zero. This results in the first term on the right-hand side of Eq. 3 evaluating to zero. Carrying out integration for the remaining terms gives the two-dimensional current continuity equation:

$$
\nabla \cdot \mathbf{J}=\frac{1}{R_{E} L}\left(\frac{\partial L J_{L}}{\partial L}+\frac{\partial J_{\varphi}}{\partial \varphi}\right)=0,
$$

where components $J_{L}$ and $J_{\varphi}$ of the integrated current density $(\mathbf{J})$ are given by: 


$$
\begin{aligned}
& J_{L}=\Sigma_{P}\left(E_{L}+B(L) U_{\varphi}^{P}\right)-\Sigma_{H}\left(E_{\varphi}-B(L) U_{L}^{H}\right)+g_{0} \Sigma_{P g} \\
& J_{\varphi}=\tilde{\Sigma}_{P}\left(E_{\varphi}-B(L) U_{L}^{P}\right)+\Sigma_{H}\left(E_{L}+B(L) U_{\varphi}^{H}\right)-g_{0} \Sigma_{H g},
\end{aligned}
$$

where $E_{L}, E_{\varphi}, B(L)$, and $g_{0}$ are measured in the magnetic equatorial plane. The three-dimensional quantities in Eq. 1 and 2 have been replaced with the field line integrated quantities. More specifically, $\Sigma_{P}$ and $\Sigma_{H}$ are the field line integrated Pedersen and Hall conductances, respectively. The tilde in $\tilde{\Sigma}_{P}$ represents the Pedersen conductance with slightly different geometric scale factors used in integration. The terms $U_{\varphi}^{P}, U_{L}^{H}, U_{L}^{P}$, and $U_{\varphi}^{H}$ are the average magnetic neutral winds along the field line weighted by the Pedersen and Hall conductivities. Finally, $\Sigma_{P g}$ and $\Sigma_{H g}$ are the sum of the field line integrated Pedersen and Hall conductivites for the ion species scaled by the mass-to-charge ratio. The exact definition of these integrated quantities is given in Appendix A.

Using the electrostatic potential $(\Phi)$, the perpendicular electric fields in the equatorial plane are given by:

$$
\begin{aligned}
& E_{L}=-\frac{1}{R_{E}} \frac{\partial \Phi}{\partial L} \\
& E_{\varphi}=-\frac{1}{R_{E} L} \frac{\partial \Phi}{\partial \varphi}
\end{aligned}
$$

Substituting Eqs. 5-8 into Eq. 4 and rearranging the terms, we find the dynamo equation:

$$
\begin{aligned}
\frac{\partial}{\partial L}\left(L \Sigma_{P} \frac{\partial \Phi}{\partial L}\right)+\frac{1}{L} \frac{\partial}{\partial \varphi}\left(\tilde{\Sigma}_{P} \frac{\partial \Phi}{\partial \varphi}\right)-\frac{\partial \Sigma_{H}}{\partial L} \frac{\partial \Phi}{\partial \varphi}+\frac{\partial \Sigma_{H}}{\partial \varphi} \frac{\partial \Phi}{\partial L} \\
=\frac{\partial}{\partial L} R\left[B\left(\Sigma_{P} U_{\varphi}^{P}+\Sigma_{H} U_{L}^{H}\right)+g_{0} \Sigma_{P g}\right] \\
\quad+\frac{\partial}{\partial \varphi} R_{E}\left[B\left(\Sigma_{H} U_{\varphi}^{H}-\tilde{\Sigma}_{P} U_{L}^{P}\right)-g_{0} \Sigma_{H g}\right]
\end{aligned}
$$

Given user-defined ionosphere and thermosphere inputs, DINAMO computes all the coefficients for and solves Eq. 9. Additionally, it computes the electric field components from the potential solution and outputs estimates for the $\mathbf{E} \times \mathbf{B}$ drifts.

\subsection{The solution domain and grid}

Specification of the two-dimensional plane that defines the magnetic equator is done using realistic magnetic field lines specified by the 2012 version of the International Geomagnetic Reference Field (IGRF-12). The IGRF-12 model describes Earth's large-scale magnetic field (1900-present) using observations from a global collection of ground-based magnetic observatories (Thébault et al. 2015).

The grid extends from 90 up to $20,000 \mathrm{~km}$ and has nonuniform spacing in apex heights with $5 \mathrm{~km}$ spacing below $2000 \mathrm{~km}$, and $500 \mathrm{~km}$ spacing above $2000 \mathrm{~km}$. The grid has a resolution of $4^{\circ}$ in geographic longitude.

The potential is set to zero at the upper boundary of the grid $(R=20,000 \mathrm{~km})$. At the lower boundary $(R=$ $90 \mathrm{~km}$ ), the model uses the Neumann boundary condition $\partial \Phi / \partial L=0$. These boundary conditions are the same as those used internally for the potential solver in SAMI3 (Huba et al. 2010). These boundary conditions do not strongly impact the results for the potential at interior points.

\subsection{Collision frequency and conductivity}

The Pedersen and Hall conductivities for a multi-species plasma $\left(\mathrm{H}^{+}, \mathrm{He}^{+}, \mathrm{O}^{+}, \mathrm{O}_{2}^{+}, \mathrm{NO}^{+}\right)$are given by:

$$
\begin{gathered}
\sigma_{P}=\frac{n_{e} e}{B} \frac{\kappa_{e}}{1+\kappa_{e}^{2}}+\sum_{i} \frac{n_{i} e}{B} \frac{\kappa_{i}}{1+\kappa_{i}^{2}} \\
\sigma_{H}=\frac{n_{e} e}{B} \frac{\kappa_{e}^{2}}{1+\kappa_{e}^{2}}-\sum_{i} \frac{n_{i} e}{B} \frac{\kappa_{i}^{2}}{1+\kappa_{i}^{2}},
\end{gathered}
$$

where $\kappa_{e, i}=\Omega_{e, i} / v_{e, i}$ is the gyro-frequency $\left(\Omega_{e, i}\right)$ to collision frequency $\left(v_{e, i}\right)$ ratio, and the summation is over all of the ion species. The subscripts $e$ and $i$ refer to electron and ion species, respectively. The ion densities $\left(n_{i}\right)$ and electron plasma density $\left(n_{e}=\sum_{i} n_{i}\right)$ are in $\mathrm{m}^{-3}$.

The gyro-frequency is given by:

$$
\Omega_{e, i}=e B / m_{e, i},
$$

where the magnetic field strength $(B)$ is provided by IGRF-12.

The collision frequencies for ions and electrons only consider collisions with neutral species. The non-resonant and temperature-dependent resonant collision frequencies for the ions are described in Schunk and Nagy (2009) with the updated coefficients for $\mathrm{O}^{+}, \mathrm{O}_{2}^{+}$, and $\mathrm{NO}^{+}$provided by Ieda (2020). The non-resonant ionneutral collision frequencies have the form:

$$
v_{i n}=C_{i n} n_{n} \quad \text { (non-resonant), }
$$

where $n_{n}$ is the neutral species density in $\mathrm{cm}^{-3}$ and $C_{i n}$ is the coefficient. Table 1 shows the non-resonant ionneutral collision frequency coefficients $\left(C_{i n} \times 10^{10}\right)$ for each ion species with the six species of neutrals used in the model $\left(\mathrm{H}, \mathrm{He}, \mathrm{N}, \mathrm{O}, \mathrm{N}_{2}, \mathrm{O}_{2}\right)$. Values marked by $\mathrm{R}$ in Table 1 represent temperature-dependent resonant 
collision frequencies and have a different form. Table 2 shows the resonant collisions frequencies. We have used the updated resonant collisions for $\mathrm{O}^{+}$and $\mathrm{O}_{2}^{+}$provided by Ieda (2020). The final collision frequency for a given ion species is:

$$
v_{i}=\sum_{n} v_{i n}
$$

where the sum is over all neutral species.

Finally, for the electron-neutral collision frequency, we use the formula provided by Nicolet (1953):

$$
v_{e}=v_{e n}=\left(5.4 \times 10^{-10}\right) n_{N} \mathrm{~T}_{\mathrm{e}}^{1 / 2},
$$

where $n_{N}$ is the sum of neutral densities in $\mathrm{cm}^{-3}$, and $\mathrm{T}_{e}$ is the electron temperature in Kelvin.

In this work, the temperatures and densities for the ions and electrons are specified by the 2016 version of the International Reference Ionosphere (IRI-2016). IRI-2016 is the result of a global effort to model the parameters in the Earth's ionosphere using a variety of ground and satellite measurement techniques (Bilitza et al. 2017).

Temperatures and densities for neutral species are provided by the 2000 version of Naval Research Laboratory Mass Spectrometer and Incoherent Scatter Radar (NRLMSISE-00) model (Picone et al. 2002). NRLMSISE-00 is an empirical model of the neutral atmosphere extending from the ground to the exobase derived using a combination of ground, rocket, and satellite-based measurements to predict neutral temperatures and densities.

\subsection{Neutral winds}

The $E$ - and $F$-region neutral wind dynamos are the primary drivers for the electric fields in the low-latitude ionosphere (Eccles 1998, 2004; Heelis 2004; Heelis et al. 1974; Maute et al. 2012). Model results in this work use neutral winds provided by the 2014 version of the Horizontal Wind Model (HWM14). HWM is an empirical model commonly used for global specification of the upper atmospheric general circulation patterns and migrating tides. The current HWM14 version is developed using a total of $\sim 73 \times 10^{6}$ observations from 44 different instruments spanning over 60 years (Drob et al. 2015).

HWM specifies the geographic zonal $(\mathrm{U})$ and meridional (V) neutral winds. The field line integrated quantities of interest, however, require the magnetic zonal $\left(u_{\phi}\right)$ and magnetic meridional $\left(u_{p}\right)$ winds which are found by projecting the HWM geographic winds onto the unit vectors in the magnetic zonal $\left(\mathbf{e}_{\phi}\right)$ and magnetic meridional $\left(\mathbf{e}_{p}\right)$ directions. These units vectors are determined locally from IGRF-12, which provides spherical components (eastward, northward, and upward) of the magnetic field.

\subsection{Field line integration}

Realistic magnetic field lines are traced out through each point of the magnetic equatorial grid using IGRF12. Tracing starts at the magnetic equator and extends down to $80 \mathrm{~km}$ in altitude. Non-uniform spacing is used for points along the field line. Field line points are spaced every $1 \mathrm{~km}$ in altitude below $110 \mathrm{~km}$. Between 110 and $2000 \mathrm{~km}$ points are spaced every $5 \mathrm{~km}$ in altitude, and above $2000 \mathrm{~km}$ points are spaced every $100 \mathrm{~km}$. This is done to better capture the structure of the ionosphere and thermosphere at lower altitudes.

Integration is done with respect to magnetic latitude. In this work, quasi-dipole magnetic latitudes are used and defined by Laundal and Richmond (2017):

$$
\lambda= \pm \cos ^{-1} \sqrt{\frac{R_{E}+h}{R_{E}+h_{A}}},
$$

where $h$ is the height of the field line point, and $h_{A}$ is the apex height of the field line.

To simplify integration, the geometric scale factors $h_{q}$, $h_{p}$ and $h_{\phi}$ in Eq. 3 are derived from dipole field lines.

\subsection{MUDPACK}

MUDPACK is a software library for geophysics developed at NCAR. Equation 9 is solved using a MUDPACK subroutine that produces a second order finite difference approximation for two-dimensional non-separable elliptic partial differential equations using multigrid iteration that combines the classical Gauss-Seidel line relaxation technique on finer grids with a coarse-grid correction procedure. Detailed information regarding this technique can be found in Adams (1989) and the references therein. MUDPACK takes the coefficients of Eq. 9 as well as specified boundary conditions as input. As mentioned earlier, MUDPACK is the same software used by NCAR's TIEGCM (Maute 2018) for the solution of the ionospheric electric potential.

\section{Results and discussion}

We now present and discuss results of DINAMO simulations in two distinct applications.

First, we use DINAMO to evaluate the ability of current climatological drivers (HWM14, IRI-2016, and NRLMSISE-00) to produce realistic ionospheric electrodynamics for different seasons and solar flux conditions (Sect. 3.1). We assess DINAMO results by comparing modeled zonal and vertical equatorial $\mathbf{E} \times \mathbf{B}$ drifts with observations. Next, we use DINAMO to quantify the contribution of the integrated vertical current $\left(J_{L}\right)$ to the morphology of the drifts (Sect. 3.1.1). 
Focus is given to results for the Peruvian longitude sector $\left(\sim 284^{\circ} \mathrm{E}\right)$, which allows a comparison of model drift results with mean plasma drifts derived from long-term Jicamarca ISR observations.

\subsection{On DINAMO equatorial $E \times B$ plasma drifts}

Figures 2 and 3 show DINAMO results for the equatorial zonal and vertical $\mathbf{E} \times \mathbf{B}$ plasma drifts, respectively. The DINAMO model results are represented by the blue curves. They show the behavior of the zonal and vertical plasma drifts as a function of local time for different seasons (rows) and solar flux conditions (columns) for the Peruvian sector at an altitude of $360 \mathrm{~km}$. The top, middle, and bottom rows correspond to December solstice, equinox, and June solstice conditions, respectively. More specifically, DINAMO model results are for day-of-year 21 (December solstice), 172 (June solstice) and 264 (equinox). The left column in each Figure corresponds to low solar flux (LSF) conditions, and the right column corresponds to high solar flux (HSF) conditions. The solar and geomagnetic input conditions of the climatological models that were input for the DINAMO simulations were chosen to match the average conditions of Jicamarca ISR observations presented by Shidler et al. (2019) and available to this study. DINAMO simulations use climatological drivers set for $F_{10.7}$ of 80 SFU and 150 SFU representing LSF and HSF conditions, respectively. During June solstice, however, we use 130 SFU to represent the HSF conditions. Finally, these simulations results are for geomagnetically quiet conditions with the climatological drivers set to $\mathrm{Kp}=2(\mathrm{Ap}=7)$.

For comparison purposes, Figs. 2 and 3 also show Jicamarca observations which are represented by the green curves. These observations were derived and first presented by Shidler et al. (2019). Shidler et al. (2019) estimated the mean behavior of geomagnetically quiet vertical and zonal plasma drifts as a function of local time and altitude (range between 200 and $600 \mathrm{~km}$ ) from observations made by the Jicamarca ISR between 1986 and 2017. The mean drifts were derived for three seasonal bins: December solstice (Jan, Feb, Nov, Dec), equinox (Mar, Apr, Sep, Oct), and June solstice (May, Jun, Jul, Aug). The drifts were further split into a low solar flux bin with an average $F_{10.7}$ of $80 \mathrm{SFU}$, for all seasons, and a high solar flux bin with an average $F_{10.7}$ of $150 \mathrm{SFU}$ for December solstice and equinox and an average of 130 SFU for June solstice. The difference in mean solar flux for June solstice was caused by lack of data. The average
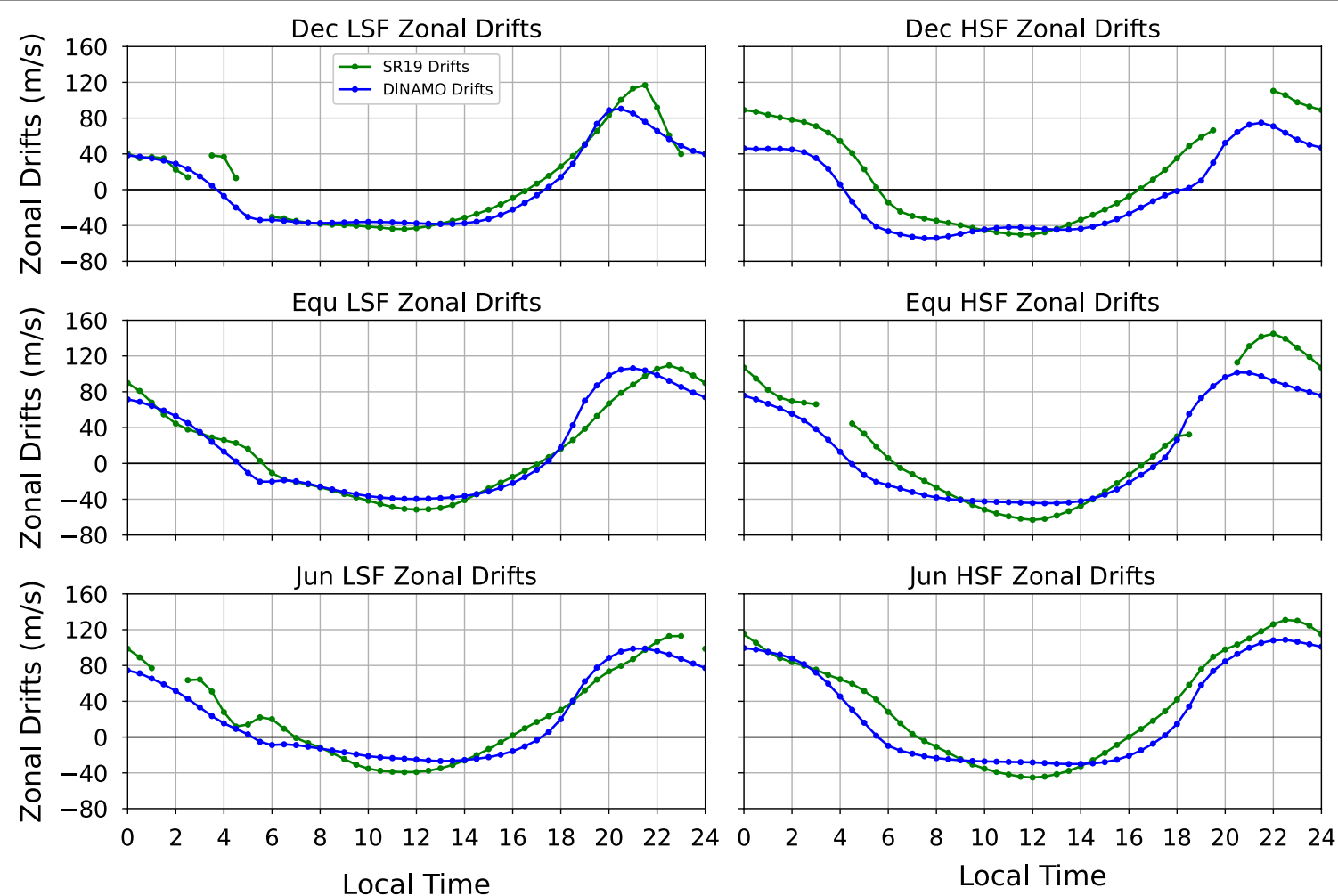

Fig. 2 Behavior of the zonal plasma drifts as a function of local time for different seasons (rows) and solar flux conditions (columns). The blue curves represent results from the DINAMO model at $360 \mathrm{~km}$. The green curves represent the Jicamarca ISR observations presented by Shidler et al. (2019) for altitudes of $360 \pm 40 \mathrm{~km}$ 

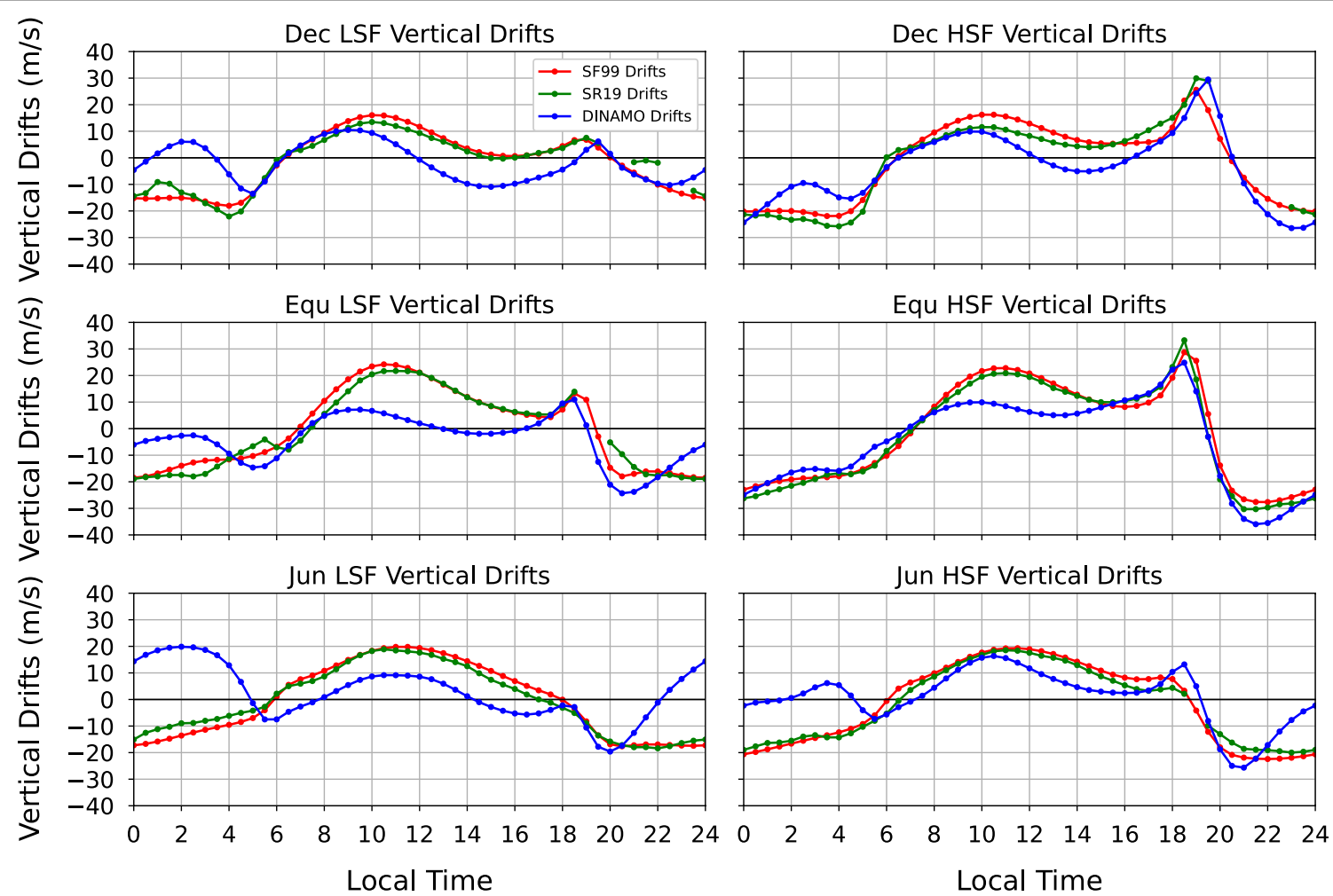

Fig. 3 Behavior of the vertical plasma drifts as a function of local time for different seasons (rows) and solar flux conditions (columns). The blue curves represent results from the DINAMO model at $360 \mathrm{~km}$. The green curves represent the Jicamarca ISR observations presented by Shidler et al. (2019) for altitudes of $360 \pm 40 \mathrm{~km}$. The red curves correspond to vertical drifts predicted by the SF99 model

Table 1 Collision frequency coefficients $C_{\text {in }} \times 10^{10}$ for non-resonant ion-neutral interactions

\begin{tabular}{lllllll}
\hline Ion & $\mathbf{H}$ & $\mathbf{H e}$ & $\mathbf{N}$ & $\mathbf{O}$ & $\mathbf{N}_{2}$ & $\mathbf{O}_{2}$ \\
\hline $\mathrm{H}^{+}$ & $\mathrm{R}$ & 10.6 & 26.1 & $\mathrm{R}$ & 33.6 & 32.0 \\
$\mathrm{He}^{+}$ & 4.71 & $\mathrm{R}$ & 11.9 & 10.1 & 16.0 & 15.3 \\
$\mathrm{O}^{+}$ & $\mathrm{R}$ & 1.32 & 4.62 & $\mathrm{R}$ & 6.85 & 6.66 \\
$\mathrm{NO}^{+}$ & 0.69 & 0.74 & 2.79 & 2.45 & 4.36 & 4.28 \\
$\mathrm{O}_{2}^{+}$ & 0.65 & 0.70 & 2.64 & 2.32 & 4.15 \\
\hline
\end{tabular}

Table 2 Resonant ion-neutral collision frequencies. Densities are in $\mathrm{cm}^{-3}$. Ion temperatures $\left(T_{i}\right)$ and neutral temperatures $\left(T_{n}\right)$ are in Kelvin

\begin{tabular}{lll}
\hline Species & $\mathbf{T}_{\mathbf{r}}(\mathbf{K})$ & $\boldsymbol{v}_{\mathbf{i n}}\left(\mathbf{s}^{\mathbf{- 1}}\right)$ \\
\hline $\mathrm{H}^{+}, \mathrm{H}$ & $>50$ & $2.65 \times 10^{-10} n(\mathrm{H}) \mathrm{T}_{r}^{1 / 2}\left(1-0.083 \log _{10} \mathrm{~T}_{r}\right)^{2}$ \\
$\mathrm{He}^{+}, \mathrm{He}$ & $>50$ & $8.73 \times 10^{-11} n(\mathrm{He}) \mathrm{T}_{r}^{1 / 2}\left(1-0.093 \log _{10} \mathrm{~T}_{r}\right)^{2}$ \\
$\mathrm{H}^{+}, \mathrm{O}$ & $>300$ & $6.61 \times 10^{-11} n(\mathrm{O}) \mathrm{T}_{i}^{1 / 2}\left(1-0.047 \log _{10} \mathrm{~T}_{i}\right)^{2}$ \\
$\mathrm{O}^{+}, \mathrm{H}$ & $>300$ & $4.63 \times 10^{-12} n(\mathrm{H})\left(\mathrm{T}_{n}+\mathrm{T}_{i} / 16\right)^{1 / 2}$ \\
$\mathrm{O}^{+}, \mathrm{O}$ & - & $\max \left[3.68 \times 10^{-11} n(\mathrm{O}) \mathrm{T}_{r}^{1 / 2}\left(1-0.065 \log _{10} \mathrm{~T}_{r}\right)^{2}, 4.01 \times 10^{-10} n(\mathrm{O})\right]$ \\
$\mathrm{O}_{2}^{+}, \mathrm{O}_{2}$ & - & $\max \left[2.62 \times 10^{-11} n\left(\mathrm{O}_{2}\right) \mathrm{T}_{r}^{1 / 2}\left(1-0.074 \log _{10} \mathrm{~T}_{r}\right)^{2}, 4.08 \times 10^{-10} n\left(\mathrm{O}_{2}\right)\right]$ \\
\hline
\end{tabular}


Kp index for the observations was approximately 2. Missing data points in the post-sunset sector are caused by coherent echoes from ESF events contaminating measurements of the background plasma drifts. Past studies have shown the occurrence rates for these events are directly proportional to the magnitude of the PRE (e.g., Fejer et al. 1999; Huang and Hairston 2015; Smith et al. 2015) which explains more prominent gaps in December and equinox during high solar flux periods. Additionally, missing values in the early morning are the result of low quality measurements (reduced signal-to-noise ratio) during that time due to decreased plasma densities.

Finally, for completeness, the red curves (in Fig. 3 only) represent the vertical drifts predicted by the Scherliess and Fejer (1999) climatological model (SF99). SF99 is a global model of the equatorial vertical drifts derived from in situ measurements made by the Atmospheric Explorer E (AE-E) satellite with additional measurements in the Peruvian sector made by the Jicamarca ISR between 1968 and 1992 (Scherliess and Fejer 1999).

A comparison of model results and measurements in Figs. 2 and 3 serve to show that DINAMO is capable of producing realistic estimates of the zonal and vertical plasma drifts. That is, it shows most of the features expected for the vertical and zonal drifts based on previous studies and observations. This is an indication of the fair representation of the ionospheric electrodynamics by the underlying driving conditions provided by the input climatological models (IRI2016, HWM14 and NRLMSISE-00).

Here, we must mention the good agreement of our results with those of the recent work of Eccles and Valladares (2021). They coincidentally also evaluated the impact of climatological models on producing realistic equatorial plasma drifts. However, they used the Electric Field Model-EFM (Eccles 2004) and focused on proper tide specification for a single solar flux condition $\left(F_{10.7}=\right.$ 110 SFU). More importantly, perhaps, is that their results reinforce the correctness of DINAMO and provide independent evidence of some of our findings. To avoid repetition, we highlight some aspects that were not addressed by Eccles and Valladares (2021).

\subsubsection{On DINAMO F-region zonal drifts}

Figure 2 shows that DINAMO, when driven by current climatological models (HWM14, IRI-2016 and NRLMSISE-00), is capable of reproducing the expected diurnal variability of the zonal drifts. More specifically, it is capable of producing the expected weak westward drifts during the day (e.g., Fejer et al. 2005, 1991), a rapid eastward acceleration in the post-sunset sector, and strong eastward plasma drifts at night. Therefore, current climatological drivers are capable of reproducing the main features of the equatorial zonal drifts including an eastward super-rotation of the ionosphere which is in good agreement with previous experimental studies (Pacheco et al. 2011).

There are, however, noticeable differences between model and observations. In all seasons and for all solar flux conditions, the reversal time for the modeled drifts occur at an earlier time in the morning, and at a later time in the evening compared to the observations. Additionally, the nighttime eastward modeled drifts tend to be weaker than the observations. Eccles and Valladares (2021) also found weaker model zonal drifts compared to observations. Here, we point out that our results indicate that the discrepancy between nighttime modeled and observed drifts is more accentuated during HSF conditions. Given the strong correlation between the motion of the plasma and neutrals during this time (e.g., Biondi et al. 1988; Chapagain et al. 2013; Fejer 1993; Fejer et al. 1985; Navarro and Fejer 2020), this behavior most likely stems from the specification of the $F$-region thermospheric neutral winds provided by HWM14. In a recent study, Navarro and Fejer (2019) compared quiet time values of the nighttime neutral winds predicted by HWM14 with observed neutral winds in the Peruvian sector during moderate solar flux conditions. They found, for example, that HWM14 significantly underestimates the eastward winds in the pre-midnight sector during equinox. Furthermore, HMW14 better represents moderate solar flux conditions. It does not include a solar flux dependency, and the observational database used in the derivation of HWM14 corresponds to measurements made during moderate solar activity with an average $F_{10.7}$ of 107 SFU (Drob et al. 2015).

\subsubsection{On DINAMO F-region vertical drifts}

We now turn our attention to the vertical drifts output by DINAMO which are illustrated by the results shown in Fig. 3.

Similar to our findings for the zonal drifts, the results indicate that the climatological drivers can produce most of the features expected for equatorial vertical drifts based on previous theoretical and experimental studies. We start by pointing out that the drivers are capable of reproducing the PRE during equinox and December solstice. The model is also capable of reproducing the increase in the PRE magnitude with solar flux which has been observed in previous studies (e.g., Fejer et al. 2008, 1991). Additionally, the magnitude of the PRE modeled by DINAMO is in fair agreement with the observations (within around $10 \mathrm{~m} / \mathrm{s}$ ). More noticeable is the excellent agreement of the PRE peak times and of the times when the drifts revert from upward to downward. 


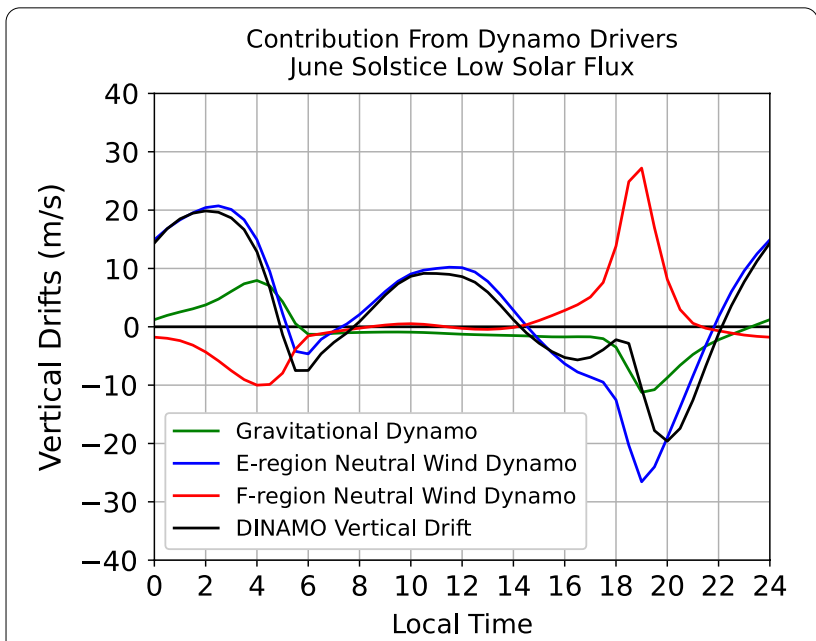

Fig. 4 Jicamarca vertical drifts (black line) due to the gravitation dynamo (green line), the E-region dynamo (blue line), and the F-region dynamo (red line)

Figure 3 also shows obvious differences between modeled and observed vertical drifts. For instance, the climatological drivers tend to produce daytime drifts that depart from the observations. More specifically, the results show weak peak values and downward vertical drifts in the afternoon. Additionally, the results show that these discrepancies are more evident during LSF (all seasons) and December solstice of HSF conditions. Eccles and Valladares (2021) also found that the tidal representation in HWM does not produce daytime drifts that match the predictions of the SF99 model. For instance, close inspection of their Fig. 4c shows the afternoon downward drifts for $F_{10.7}=110 \mathrm{SFU}$ conditions as well.

Here, we must point out that our modeled daytime drifts resemble those seen by C/NOFS during the extreme solar flux conditions of 2008/2009. For instance, Stoneback et al. (2011) examined median values of the meridional plasma drifts using observations from the $\mathrm{C} /$ NOFS satellite and found downward afternoon drifts in all seasons for certain longitude sectors. Stoneback et al. (2011) proposed the increased role of the semi-diurnal tide in the $E$-region to explain downward afternoon drifts.

Additionally, perhaps the most striking difference between modeled and observed vertical drifts occur at night during LSF conditions, particularly in June solstice. Figure 3 shows that the climatological models driving DINAMO produce nighttime drifts that depart significantly from the observations during LSF conditions. In particular, large upward drifts are seen in June solstice when observations show downward drifts. Again, Fig. 4c in Eccles and Valladares (2021) also shows these abnormal drifts developing in May-July.
The section below presents results related to the sources of the unusual behavior in the model $F$-region drifts.

\subsubsection{Abnormal nighttime F-region drifts}

In order to identify the origin of the abnormal upward drifts described above, we follow the approach of previous studies (e.g., Eccles 2004; Maute et al. 2012) and isolate different source terms to evaluate their relative contribution to the overall vertical drifts. Figure 4 shows June solstice LSF vertical drifts decomposed into contributions from the gravitational dynamo (green curve), from the $E$-region neutral wind dynamo (blue curve), and from the $F$-region neutral wind dynamo (red curve). The total vertical drifts (all source terms included) is shown as the black curve. The contribution from the gravitational dynamo to the vertical drifts is found by setting the neutral winds to zero everywhere and solving Eq. 9. For the contribution from the E-region dynamo, gravity driven currents and neutral winds in the F-region are set to zero. Finally, the contribution from the F-region dynamo is found by setting gravity driven currents and neutral winds in the E-region to zero. Note that the E-region and $F$-region neutral wind dynamos are determined by decomposing the integrals in Eqs. 18d-18g (Appendix A) into a sum of integrals. Field line points below $200 \mathrm{~km}$ contribute to the $E$-region dynamo term, and points above $200 \mathrm{~km}$ contribute to the $F$-region dynamo. For instance, when determining the contribution of the $F$-region dynamo, the winds below $200 \mathrm{~km}$ and respective integrals are set to zero.

We start by pointing out that Fig. 4 shows that the gravitational term in DINAMO produces the same effect shown by the Eccles (2004) model. That is, the gravitational dynamo modifies the vertical drifts by 5 and $15 \mathrm{~m} / \mathrm{s}$ near the solar terminators. During these times, the conductivity is rapidly changing, and zonal electric fields near the terminators are set up to keep currents divergence-free.

More importantly, Fig. 4 shows that the $E$-region neutral wind dynamo, as described by the input climatological models, is responsible for both the downward drifts in the late afternoon and upward drifts at night.

Finally, we point out that HWM14 does not include a solar flux dependency causing the neutral wind descriptions to be the same for both LSF and HSF conditions. Therefore, the reduction in downward drifts in the afternoon and upward drifts in the post-midnight sector from LSF to HSF conditions indicates that the $E$-region winds do play a role in these features, but their contribution is heavily modulated by the conductivities. 


\subsubsection{Height variation of F-region drifts}

So far we focused on model results for a single height near the $F$-region peak $(\sim 360 \mathrm{~km})$. It is known, however, that vertical and zonal drifts can vary with height, particularly during evening and nighttime hours (Fejer et al. 2014; Hui and Fejer 2015; Kudeki and Bhattacharyya 1999; Lee et al. 2015; Nayar and Sreehari 2004; Richmond et al. 2015; Rodrigues et al. 2012; Shidler and Rodrigues 2019).

Previous results showed that the climatological drivers can produce the overall behavior of the observed drifts. We now examine the ability of the climatological drivers to produce realistic variations of the $F$-region drifts with height. Focus is given to equinox HSF model simulations as the previous results show that the model drifts at main $F$-region heights resemble the observations and, therefore, suggest better accuracy of the input drivers. During equinox, height variations in the zonal and vertical drifts are expected to develop at least near the sunset terminator (Shidler et al. 2019).

Figure 5 shows the local time versus height variability for the vertical (top) and zonal (bottom) plasma drifts produced by DINAMO for equinox HSF conditions. It serves to show that the climatological drivers can indeed produce the altitude variability associated with equatorial plasma drifts.
For example, DINAMO results for the zonal drifts (bottom panel) show the vertical shear observed around the time of the PRE that is associated with the evening plasma vortex (Eccles et al. 1999; Haerendel et al. 1992; Richmond et al. 2015; Rodrigues et al. 2012). Daytime westward drifts also show some height variability between 0900 and 1500 LT. This is in agreement with the analysis of Hui and Fejer (2015). They showed that daytime westward drifts observed at Jicamarca, between March and October, increase with height for altitudes below $300 \mathrm{~km}$.

DINAMO results for the vertical drifts (top panel of Fig. 5) also show the expected weak height variation during most times. Height gradients, nevertheless, are positive in the morning and negative starting in the afternoon. Significant height gradients in the vertical drifts are only observed around $0400 \mathrm{LT}$ and around the time of the PRE. This behavior is consistent with the curlfree condition for ionospheric electric fields and with previous observational studies that relate noticeable height variations of the equatorial vertical $\mathbf{E} \times \mathbf{B}$ drifts to the strong longitudinal variations in the zonal drifts occurring near dawn and dusk (e.g., Murphy and Heelis 1986; Pingree and Fejer 1987; Shidler and Rodrigues 2019; Shidler et al. 2019). More specifically, at the magnetic equator, $\nabla \times \mathbf{E}=0$ leads to $\frac{2 W_{i}}{r}-\frac{\partial W_{i}}{\partial r}=\frac{1}{r} \frac{\partial U_{i}}{\partial \varphi}$,
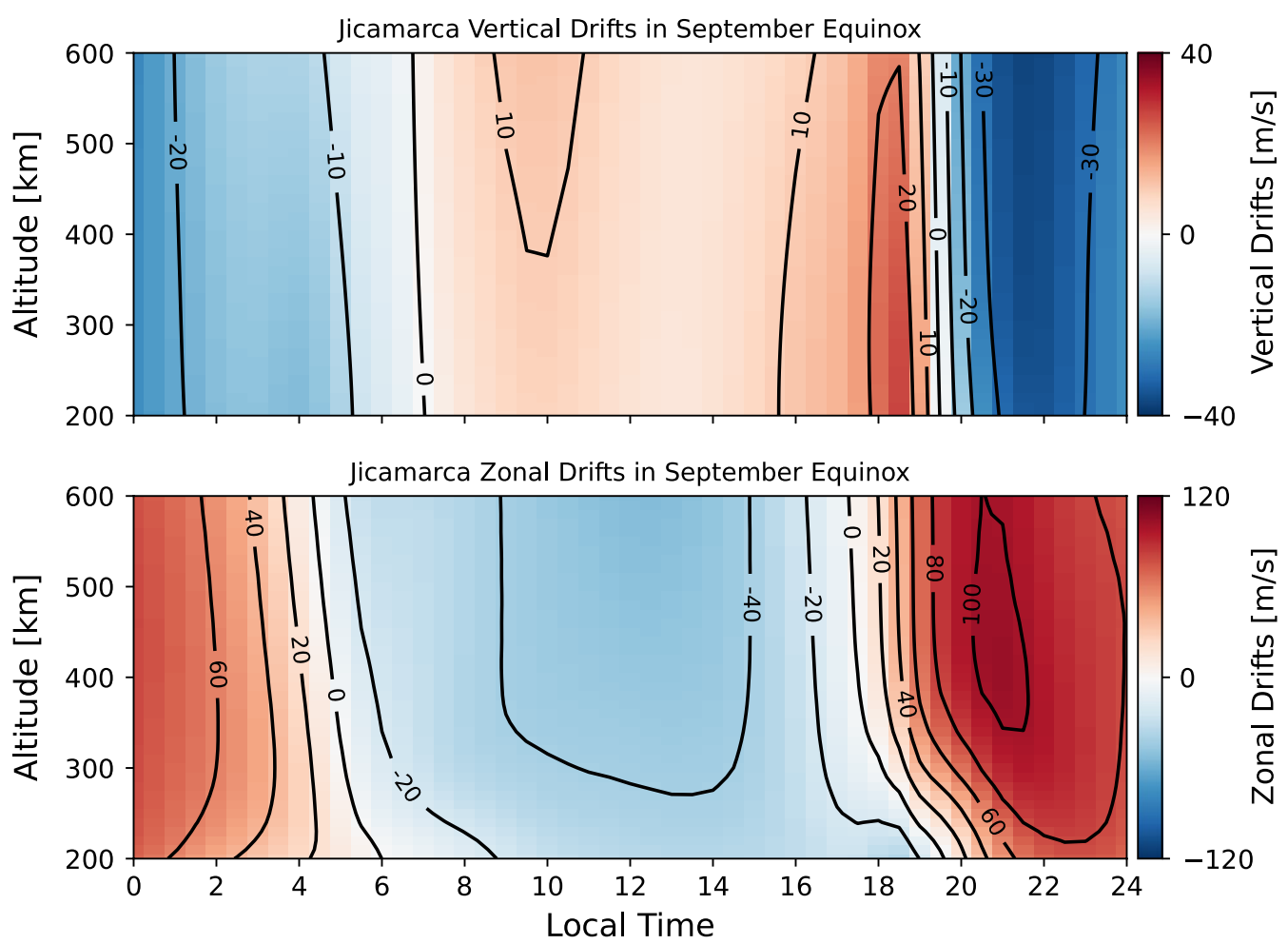

Fig. 5 Vertical (top) and zonal (bottom) plasma drifts at Jicamarca for equinox high solar flux conditions 
where $W_{i}$ and $U_{i}$ are the components of the ionospheric plasma drifts in the vertical $(r)$ and zonal $(\varphi)$ directions, respectively (Murphy and Heelis 1986).

\subsection{On the vertical integrated current $\left(J_{L}\right)$}

We now present results related to our analysis of the integrated vertical current $\left(J_{L}\right)$. More specifically, we evaluate the $J_{L}$ contribution to the morphology of the zonal drifts. Again, we focus our analysis on DINAMO simulations for equinox HSF conditions for which the drivers seem to produce drifts that best match observations.

The expression for the integrated vertical current (Eq. 5) can be rearranged to solve for the zonal plasma drifts $\left(U_{i}\right)$ at the magnetic equator:

$$
U_{i}=U_{\varphi}^{P}+\frac{\Sigma_{H}}{\Sigma_{P}} U_{L}^{H}-\frac{\Sigma_{H}}{\Sigma_{P}} W_{i}-\frac{J_{L}}{B \Sigma_{P}}-\frac{g_{0} \Sigma_{P g}}{B \Sigma_{P}},
$$

where $W_{i}$ is vertical plasma drift. Equation 17 has been used in the past (Haerendel et al. 1992) to describe the morphology of the zonal plasma drifts in terms of two-dimensional field line integrated quantities of the ionosphere.

A simplified version of Eq. 17 that only takes into consideration the $U_{\varphi}^{P}$ and $-\frac{\Sigma_{H}}{\Sigma_{P}} W_{i}$ terms has been commonly used to interpret observations of the zonal drifts (e.g., Chau and Woodman 2004; Hui and Fejer 2015; Richmond et al. 2015; Rodrigues et al. 2012). More recently, Shidler and Rodrigues (2021) analyzed the ability of Eq. 17 to reproduce observed zonal plasma drifts made at Jicamarca given field line integrated quantities specified by climatological models aided by mean vertical drifts derived from Jicamarca ISR observations. However, like in previous studies, the fourth term $\left(-\frac{J_{L}}{B \Sigma_{p}}\right)$, however, had to be neglected since $J_{L}$ could not be estimated from the models alone.

Haerendel et al. (1992) and Eccles et al. (2015) examined the impact of the $-\frac{J_{L}}{B \Sigma_{p}}$ term, with emphasis on the period around 1900 LT when a shear in the zonal plasma drifts is commonly observed (e.g., Kudeki and Bhattacharyya 1999; Lee et al. 2015; Shidler et al. 2019). Additionally, it was simply assumed that $J_{L}$ was positive and roughly constant with height having a magnitude of only a few $\mathrm{mA} / \mathrm{m}$. Therefore, the altitude variability was controlled by $\Sigma_{P}$ which is significantly reduced in the bottomside and, therefore, the fourth term predicted strong westward drifts in the bottomside and weak drifts at higher altitudes. This behavior acts to enhance the vertical shear in the zonal plasma drifts.

DINAMO simulations now allow us to better estimate the contribution of the $-\frac{J_{L}}{B \Sigma_{p}}$ term to the morphology $F$-region zonal drifts. Figure 6 shows the contributions from each term on the right-hand side of Eq. 17 to the zonal drifts as a function of local time and height. The results are for the Jicamarca longitude sector. While the total zonal drifts are shown in panel (a), the contribution from the five terms are shown in panels $(b-f)$.

The magnitude and behavior of the first three terms panels $(b-d)$ are in agreement with the results of Shidler and Rodrigues (2021). That is the Pedersen-weighted magnetic zonal winds $\left(U_{\varphi}^{P}\right)$ in panel (b) are primarily responsible for most of the observed features of the zonal plasma drifts including the diurnal variability and the vertical shear commonly seen in the post-sunset sector. Shidler and Rodrigues (2021) also found that the contribution from the Hall-weighted meridional winds $\left(U_{L}^{H}\right)$ in panel (c) was negligible throughout the day.

The $-\frac{\Sigma_{H}}{\Sigma_{P}} W_{i}$ term (panel d) during daytime (when the Hall-to-Pedersen ratio is close to 1) makes a contribution to the zonal drifts with absolute values that are similar to those of the vertical drifts $\left(W_{i}\right)$.

Perhaps more importantly, this term also makes significant contributions $(\sim 20 \mathrm{~m} / \mathrm{s})$ to the zonal drifts in the bottomside during nighttime acting as to enhance the shear around the time of the PRE ( $\sim 1900$ LT). Here, we must point out that recent studies linked the development of ESF to the Collisional Shear (CS) instability and to the strength of the vertical shear in the zonal drifts (Aveiro and Hysell 2010; Hysell and Kudeki 2004; Kudeki et al. 2007) The results, however, indicate that the strength of the shear is dictated by the magnitude of the PRE, which is more traditionally recognized as the most important driver of the Generalized Rayleigh-Taylor (GRT) instability leading to ESF.

The gravitational term is shown in panel (f), and has negligible contribution to the overall plasma drifts but is included here for completeness.

Finally, the contribution from the $-\frac{J_{L}}{B \Sigma_{p}}$ term is shown in panel (e). Throughout most of the day, the contribution from this term is negligible. There are, however, a couple of times where this term predicts drifts with magnitudes greater than $\sim 5 \mathrm{~m} / \mathrm{s}$ and that are a significant portion of the total zonal drifts. For example, between 0700 and $1000 \mathrm{LT}$ at altitudes above about $500 \mathrm{~km}$. Additionally, as suggested by Haerendel et al. (1992), the $-\frac{J_{L}}{B \Sigma_{P}}$ term contributes with relatively strong (up to $\sim 16 \mathrm{~m} / \mathrm{s}$ ) westward plasma drifts between 1900 and $2100 \mathrm{LT}$ at bottomside $F$-region heights (below $\sim 300 \mathrm{~km}$ ) and weaker drifts $(\sim 10 \mathrm{~m} / \mathrm{s})$ at higher altitudes.

Figure 7 provides a closer look at the behavior and impact of $J_{L}$ on zonal drifts. It shows (apex) height profiles of various parameters for 1900 LT (top) and 2000 LT (bottom). Panels (a1) and (a2) show altitude profiles of the modeled zonal drifts and three of the terms (right hand side of equation 17) contributing to them. The $\frac{\Sigma_{H}}{\Sigma_{P}} U_{L}^{H}$ and $-\frac{g_{0} \Sigma_{P g}}{B \Sigma_{P}}$ terms are not shown since they do not make noticeable contributions at these times. Panels (b1) 

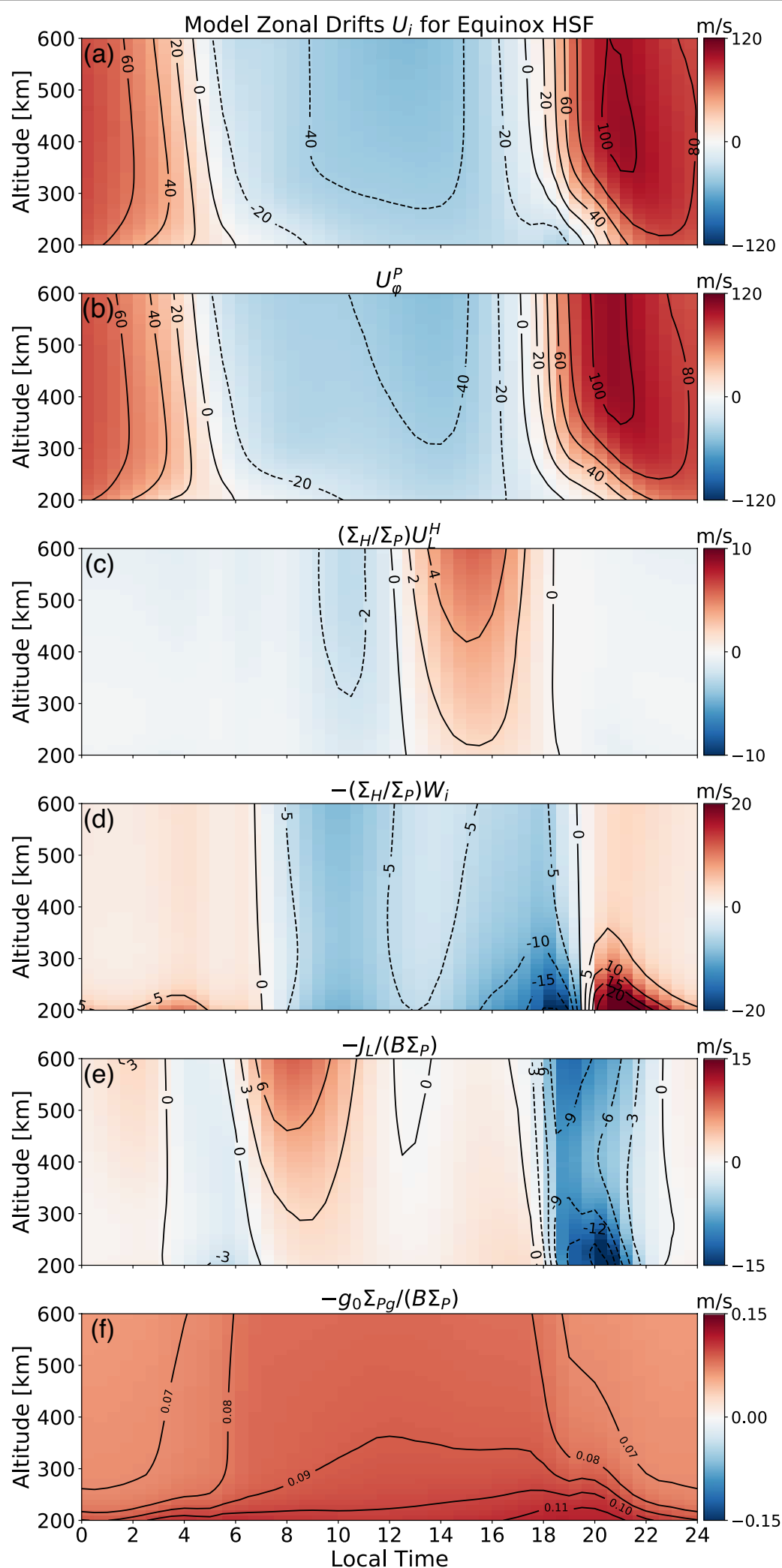

Fig. 6 a Zonal drifts modeled by DINAMO for equinox HSF conditions and $\mathbf{b}$-f contributions from different terms of Eq. 17 to these drifts. All values are given in $\mathrm{m} / \mathrm{s}$ 

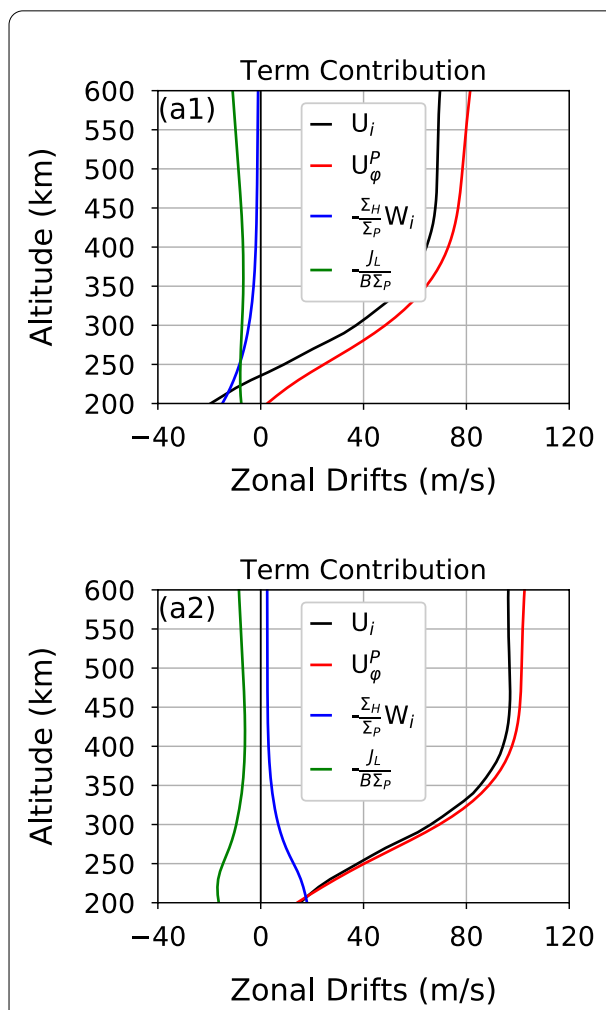
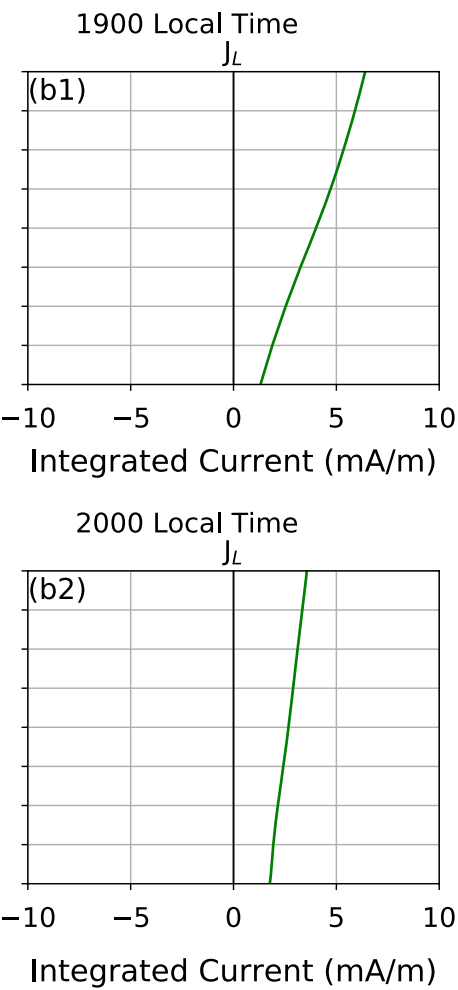
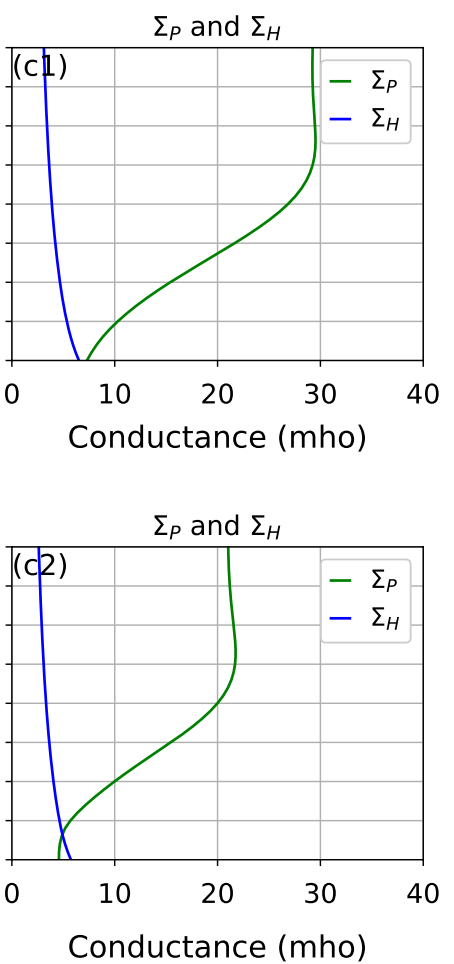

Fig. 7 On the contribution of $J_{L}$ to the morphology of the zonal plasma drifts at $1900 \mathrm{LT}$ (top) and $2000 \mathrm{LT}$ (bottom). Panels a1 and a2 show the apex height profiles of the zonal plasma drifts modeled by DINAMO for equinox HSF conditions. Panels b1 and b2 show apex height profiles $J_{L}$. Finally, panels $\mathrm{c} 1$ and c2 shows apex height profiles of Pedersen and Hall conductances

and (b2) show the height profile of $J_{L}$. Finally, panels (c1) and (c2) show height profiles of the field line integrated conductances.

At 1900 LT the vertical drifts are still positive (upward). See Fig. 5. At this time, the Pedersen conductance also increases significantly with height up to $\sim 400 \mathrm{~km}$, while the Hall conductance decreases moderately with height as shown in panel (c1). Therefore, the $-\frac{\Sigma_{H}}{\Sigma_{P}} W_{i}$ term contributes with westward drifts more significantly in the bottomside $F$-region as indicated in panel (a1). Around this time, $J_{L}$ increases with height (panel b1) and $-\frac{J_{L}}{B \Sigma_{P}}$ contributes westward drifts that are nearly constant with height. Therefore, the $-\frac{L_{L}}{B \Sigma_{P}}$ term acts to reduce the eastward $F$-region plasma drifts that are driven by the wind dynamo term $\left(U_{\varphi}^{P}\right)$. The $-\frac{J_{L}}{B \Sigma_{P}}$ term also increases the altitude of the transition height between westward and eastward plasma drifts from $200 \mathrm{~km}$ to about $245 \mathrm{~km}$. The result is a strong vertical shear in the zonal drifts around the PRE time that can be seen in panel (a) of Fig. 6.

At 2000 LT the behavior of $J_{L}$ more closely resembles the situation assumed by Haerendel et al. (1992). That is, $J_{L}$ is positive (upward) and is nearly constant with altitude with a magnitude of a few $\mathrm{mA} / \mathrm{m}$. The overall behavior of the conductances do not change much from that of $1900 \mathrm{LT}$. Therefore, the $-\frac{J_{L}}{B \Sigma_{P}}$ term continues to drive westward drifts with larger magnitudes at bottomside heights. At 2000 LT, however, the vertical drifts are downward (see Fig. 5). This causes the $-\frac{\Sigma_{H}}{\Sigma_{P}} W_{i}$ to drive eastward drifts and nearly cancel the westward drifts driven by $-\frac{J_{L}}{B \Sigma_{P}}$. Therefore, during this time the zonal drifts are more completely controlled by $U_{\varphi}^{P}$.

\section{Conclusions}

We introduced a new numerical model of the ionospheric electrodynamics that will be used as a tool to aid in Data Interpretation and Numerical Analysis of ionospheric Missions and Observations (DINAMO). The model numerically solves the ionospheric dynamo equation using user-specified inputs for the global state of the I-T system. In this work, the I-T system is specified by IRI-2016, HWM14, NRLMSISE-00, and IGRF-12 which are widely used climatological models within the space science community.

Most of DINAMO has been written entirely in Python. Using Python facilitates modifications in the input drivers and the setup of numerical experiments. Additionally, Python is a popular programming language will help to 
engage students in numerical modeling applied to space sciences.

In the current version of DINAMO, the polarization electric fields and associated plasma drifts are driven by the neutral wind and gravitational dynamos. The main features of the predicted vertical and zonal plasma drifts can be attributed to the neutral wind dynamo, while the gravitational dynamo can modify the vertical drifts by $5-15 \mathrm{~m} / \mathrm{s}$ near dawn and dusk, which is good agreement with previous studies (Eccles 2004).

DINAMO results were illustrated in two distinct applications. First, DINAMO was used to evaluate the extent of which current climatological I-T models (IRI2016, HWM14, NRLMSISE-00, and IGRF-12) are capable of driving a realistic description of the low-latitude electrodynamics. Modeled zonal and vertical $F$-region drifts were compared with Jicamarca ISR drifts. Second, DINAMO was used to evaluate how much the field line integrated vertical current $J_{L}$ can contribute to the morphology of the zonal plasma drifts.

With respect to the first study, some of the main findings can be summarized as follows:

- Current climatological models can drive most of the main features of the zonal and vertical plasma drifts observed by the Jicamarca ISR. This includes, for instance, the weak westward drifts during daytime and stronger eastward drifts at night. The drivers are also capable of producing the vertical shear in the $F$-region zonal plasma drifts that is commonly observed in the post-sunset sector. The height variability of the vertical drifts was found to be consistent with the expectation of curl-free electric fields $(\nabla \times \mathbf{E}=0)$. With respect to vertical drifts, we also found that the drivers can capture fairly well the variability of the PRE with both season and solar cycle. The magnitude and occurrence time of the modeled PRE are in good agreement with observations. Finally, a better agreement between model and observations for equinox HSF conditions indicate a more accurate description of the I-T state by the climatological models for these geophysical conditions.

- Our analyses also identified abnormal features in the drifts driven by the I-T models. For instance, DINAMO predicted different reversal times of the zonal drifts during all seasons and solar flux conditions. Additionally, the magnitude of peak nighttime eastward drifts were weaker than what was observed at Jicamarca. This discrepancy was attributed to the $F$-region neutral winds predicted by HWM14. With respect to vertical drifts, we found that the drivers tend to produce weak upward or even downward vertical drifts in the afternoon when observations show upward drifts. This effect was more exaggerated during low solar flux conditions. Additionally, the drivers tend to produce nighttime drifts that depart from the observations. We showed that this behavior was driven by the neutral wind dynamo occurring along field line points below $200 \mathrm{~km}$ in altitude.

Now, with respect to the second study, findings can be summarized as follows:

- Using model results during equinox HSF conditions, we analyzed the contribution of the $-\frac{J_{L}}{B \Sigma_{p}}$ term (Eq. 17) to the morphology of zonal plasma drifts. We found that this term only makes non-negligible contributions between 0700 and $1000 \mathrm{LT}$ and 1900 and 2100 LT. We confirmed assumptions made by Haerendel et al. (1992) that this the $-\frac{J_{L}}{B \Sigma_{p}}$ term can make significant contributions to the total zonal plasma drifts in the bottomside $F$-region ionosphere in the postsunset sector. We found contributions as large as 16 $\mathrm{m} / \mathrm{s}$ (westward) around 2000 LT. However, during this time the vertical drifts are downward and this contribution is nearly canceled by eastward drifts driven by the $-\frac{\Sigma_{H}}{\Sigma_{P}} W_{i}$ term. Around 1900 LT during the PRE, on the other hand, westward drifts driven by $-\frac{J_{L}}{B \Sigma_{p}}$ add to westward drifts driven by the $-\frac{\Sigma_{H}}{\Sigma_{P}} W_{i}$ term. As a result, this enhances the vertical shear in the zonal plasma drifts which has been associated with ESF (Aveiro and Hysell 2010; Hysell and Kudeki 2004; Kudeki and Bhattacharyya 1999; Kudeki et al. 2007).

\section{Appendix A: Field line integration}

The definitions for field line integrals used in our model come from Haerendel et al. (1992):

$$
\begin{aligned}
& \Sigma_{P}=R_{E} L \int_{\lambda_{S}}^{\lambda_{N}} \sigma_{P}\left(1+3 \sin ^{2} \lambda\right) \cos \lambda \mathrm{d} \lambda \\
& \tilde{\Sigma}_{P}=R_{E} L \int_{\lambda_{S}}^{\lambda_{N}} \sigma_{P} \cos \lambda d \lambda \\
& \Sigma_{H}=R_{E} L \int_{\lambda_{S}}^{\lambda_{N}} \sigma_{H}\left(1+3 \sin ^{2} \lambda\right)^{1 / 2} \cos \lambda \mathrm{d} \lambda \\
& U_{\varphi}^{P}=\frac{R_{E} L}{\Sigma_{P}} \int_{\lambda_{S}}^{\lambda_{N}} \sigma_{P} u_{\phi} \frac{\left(1+3 \sin ^{2} \lambda\right)}{\left(1-\sin ^{2} \lambda\right)^{3 / 2}} \cos \lambda \mathrm{d} \lambda
\end{aligned}
$$




$$
\begin{aligned}
& U_{L}^{P}=\frac{R_{E} L}{\tilde{\Sigma}_{P}} \int_{\lambda_{S}}^{\lambda_{N}} \sigma_{P} u_{p} \frac{\left(1+3 \sin ^{2} \lambda\right)^{1 / 2}}{\left(1-\sin ^{2} \lambda\right)^{3 / 2}} \cos \lambda \mathrm{d} \lambda \\
& U_{\varphi}^{H}=\frac{R_{E} L}{\Sigma_{H}} \int_{\lambda_{S}}^{\lambda_{N}} \sigma_{H} u_{\phi} \frac{\left(1+3 \sin ^{2} \lambda\right)^{1 / 2}}{\left(1-\sin ^{2} \lambda\right)^{3 / 2}} \cos \lambda \mathrm{d} \lambda \\
& U_{L}^{H}=\frac{R_{E} L}{\Sigma_{H}} \int_{\lambda_{S}}^{\lambda_{N}} \sigma_{H} u_{p} \frac{\left(1+3 \sin ^{2} \lambda\right)}{\left(1-\sin ^{2} \lambda\right)^{3 / 2}} \cos \lambda \mathrm{d} \lambda \\
& \Sigma_{P g}=\frac{R_{E}^{2}}{R} \int_{\lambda_{S}}^{\lambda_{N}} \sum_{i} \frac{\sigma_{P i} m_{i}}{e} \cos \lambda \mathrm{d} \lambda \\
& \Sigma_{H g}=\frac{R_{E}^{2}}{R} \int_{\lambda_{S}}^{\lambda_{N}} \sum_{i} \frac{\sigma_{H i} m_{i}}{e}\left(1+3 \sin ^{2} \lambda\right)^{-1} \cos \lambda \mathrm{d} \lambda
\end{aligned}
$$

where $\lambda$ is the magnetic latitude, and $\lambda_{S}$ and $\lambda_{N}$ are the magnetic latitudes at the base of the ionosphere in the magnetic south and magnetic north.

\section{Acknowledgements}

The authors would like to thank the reviewers from providing helpful comments and suggestions to improve this manuscript.

\section{Authors' contributions}

SS developed the DINAMO software, analyzed the data, produced the graphs, and made contributions to the interpretation of results and writing of this manuscript. FR provided directions for this study, interpreted results, and contributed to the writing of this manuscript. All authors read and approved the final manuscript.

\section{Funding}

Work at UT Dallas was supported by the NSF (AGS-1554926 and AGS-1916055)

\section{Availability of data and materials}

Please contact the corresponding author for data requests.

\section{Declarations}

\section{Competing interests}

The authors declare that they have no competing interest.

\section{Author details}

${ }^{1}$ William B. Hanson Center for Space Sciences, The University of Texas at Dallas, 800 W Campbell Rd, Richardson, TX 75080, USA. ${ }^{2}$ Applied Research Laboratories, The University of Texas at Austin, 10000 Burnet Rd, Austin, TX 78758, USA.

Received: 15 June 2021 Accepted: 16 December 2021

Published online: 07 January 2022

\section{References}

Abdu MA, de Medeiros RT, Bittencourt JA, Batista IS (1983) Vertical ionization drift velocities and range type spread $\mathrm{f}$ in the evening equatorial ionosphere. J Geophys Res 88:399-402. https://doi.org/10.1029/JA088 iA01p00399
Adams JC (1989) Mudpack: multigrid portable fortran software for the efficient solution of linear elliptic partial differential equations. Applied Math Comput 34:113-146. https://doi.org/10.1016/0096-3003(89)90010-6

Alken P (2016) Observations and modeling of the ionospheric gravity and diamagnetic current systems from CHAMP and Swarm measurements. J Geophys Res 121:589-601. https://doi.org/10.1002/2015JA022163

Alken P, Maus S, Richmond AD, Maute A (2011) The ionospheric gravity and diamagnetic current systems. J Geophys Res. https://doi.org/10.1029/ 2011JA017126

Anthes R, Schreiner W (2019) Six new satellites watch the atmosphere over earth's equator. EOS. https://doi.org/10.1029/2019EO131779

Aveiro HC, Hysell DL (2010) Three-dimensional numerical simulation of equatorial F region plasma irregularities with bottomside shear flow. J Geophys Res. https://doi.org/10.1029/2010JA015602

Balan N, Oyama K-I, Bailey GJ, Fukao S, Watanabe S, Abdu MA (1997) A plasma temperature anomaly in the equatorial topside ionosphere. J Geophys Res 102:7485-7492. https://doi.org/10.1029/97JA00039

Basu S, MacKenzie E, Basu S (1988) Ionospheric constraints on VHF/UHF communications links during solar maximum and minimum periods. Radio Sci 23:363-378. https://doi.org/10.1029/RS023i003p00363

Bilitza D, Altadill D, Truhlik V, Shubin VIG, Reinisch B, Huang X (2017) International reference ionosphere 2016: From ionospheric climate to real-time weather predictions. Space Weather 15:418-429. https://doi.org/10.1002/ 2016SW001593

Biondi MA, Meriwether JW, Fejer BG, Woodman R (1988) Measurements of the dynamics and coupling of the equatorial thermosphere and the $F$ region ionosphere in Peru. J Atmos Solar Terr Phys 50:937-942. https://doi.org/ 10.1016/0021-9169(88)90081-5

Carrano CS, Groves KM, Caton RG (2012) Simulating the impacts of ionospheric scintillation on I band sar image formation. Radio Sci 47:20. https://doi.org/10.1029/2011RS004956

Chapagain NP, Daniel FJ, Meriwether JW, Chau JL, Makela JJ (2013) Comparison of zonal neutral winds with equatorial plasma and plasma drift velocities. J Geophys Res 118:1802-1812. https://doi.org/10.1002/jgra.50238

Chau JL, Woodman RF (2004) Daytime vertical and zonal velocities from 150-km echoes: their relevance to F region dynamics. Geophys Res Lett 31:17801. https://doi.org/10.1029/2004GL020800

Crowley G, Fish C, Pilinski M et al, ES (2016) Scintillation observations and response of the ionosphere to electrodynamics (SORTIE). In: Proceedings of the 30th annual AIAA/USU smallsat conference, SSC16-VI-3

Drob DP, Emmert JT, Meriwether JW, Makela JJ, Doornbos E, Conde M, Hernandez G, Noto J, Zawdle KA, McDonald SE, Huba JD, Klenzing JH (2015) An update to the Horizontal Wind Model (HWM): the quiet time thermosphere. Earth Space Sci 2:301-319. https://doi.org/10.1002/2014E A000089

Eccles JV (1998) A simple model of low-latitude electric fields. J Geophys Res 103:26699-26708. https://doi.org/10.1029/98JA02657

Eccles JV (2004) The effect of gravity and pressure in the electrodynamics of the low-latitude ionosphere. J Geophys Res 109:05304. https://doi.org/10. 1029/2003JA010023

Eccles JV, Valladares C (2021) Low-latitude plasma drifts from the horizontal wind model and coupled ionopshere-electric field model. J Geophys Res. https://doi.org/10.1029/2020JA029056

Eccles JV, Maynard N, Wilson G (1999) Study of the evening plasma drift vortex in the low-latitude ionosphere using San Marco electric field measurements. J Geophys Res 104:8133-28143. https://doi.org/10.1029/1999J A900373

Eccles JV, St. Maurice JP, Schunk RW (2015) Mechanisms underlying the prereversal enhancement of the vertical plasma drift in the low-latitude ionosphere. J Geophys Res 120:4950-4970. https://doi.org/10.1002/2014/ JA020664

Fejer BG (1993) F region plasma drifts over Arecibo: solar cycle, seasonal, and magnetic activity effects. J Geophys Res 98:13635-13652. https://doi.org/ 10.1029/93JA00953

Fejer BG, Kudeki E, Farley DT (1985) Equatorial F region zonal plasma drifts. J Geophys Res 90:12249-12255. https://doi.org/10.1029/JA090iA12p12249

Fejer BG, de Paula ER, Gonzalez SA, Woodman RF (1991) Average vertical and zonal F region plasma drifts over Jicamarca. J Geophys Res 96:1390113906. https://doi.org/10.1029/91JA01171 
Fejer BG, Scherliess L, de Paula ER (1999) Effects of the vertical plasma drift velocity on the generation and evolution of equatorial spread F. J Geophys Res 104:19859-19869. https://doi.org/10.1029/1999JA900271

Fejer BG, Santos AS, Costa Pereira AE (2005) Climatology of F region zonal plasma drifts over Jicamarca. J Geophys Res. https://doi.org/10.1029/ 2005JA011324

Fejer BG, Jensen JW, Su S-Y (2008) Quiet time equatorial F region vertical plasma drift model derived from ROCSAT-1 observations. J Geophys Res. https://doi.org/10.1029/2007JA012801

Fejer BG, Hui D, Chau JL, Kudeki E (2014) Altitudinal dependence of evening equatorial F region vertical plasma drifts. J Geophys Res 119:5877-5890. https://doi.org/10.1002/2014JA019949

Haerendel G, Eccles JV, Çakir S (1992) Theory for modeling the equatorial evening ionosphere and the origin of the shear in the horizontal plasma flow. J Geophys Res 97:1209-1223. https://doi.org/10.1029/91JA02226

Heelis RA (2004) Electrodynamics in the low and middle latitude ionosphere: a tutorial. J Atmos Solar Terr Phys 66:825-838. https://doi.org/10.1016/j. jastp.2004.01.034

Heelis RA, Kendall PC, Moffett RJ, Windle DW (1974) Electrical coupling of the $E$ and $F$ regions and it's effect on the $F$ region drifts and winds. Planet Space Sci 22:743-756. https://doi.org/10.1016/0032-0633(74)90144-5

Heelis RA, Stoneback RA, Perdue MD, Depew MD, Morgan WA, Mankey MW, Lippincott CR, Harmon LL, Holt BJ (2017) Ion velocity measurements for the ionospheric connections explorer. Space Sci Rev 212:615-629. https://doi.org/10.1007/s11214-017-0383-3

Huang C (2018) Effects of the postsunset vertical plasma drift on the generation of equatorial spread F. Prog Earth Planet Sci. https://doi.org/10.1186/ s40645-017-0155-4

Huang C, Hairston MR (2015) The postsunset vertical plasma drift and its effects on the generation of equatorial plasma bubbles observed by the C/NOFS satellite. J Geophys Res 120:2263-2275. https://doi.org/10.1002/ 2014JA020735

Huang C, Wilson GR, Hairston MR, Zhang Y, Wang W, Liu J (2016) Equatorial ionospheric plasma drifts and $\mathrm{O}+$ concentration enhancements associated with disturbance dynamo during the 2015 St. Patrick's Day magnetic storm. J Geophys Res Space Phys. https://doi.org/10.1002/2016JA023072

Huba JD, Joyce G, Krall J, Siefring CL, Bernhardt PA (2010) Self-consistent modeling of equatorial dawn density depletions with SAMI3. Geophys Res Lett. https://doi.org/10.1029/2009GL041492

Hui D, Fejer BG (2015) Daytime plasma drifts in the equatorial lower ionosphere. J Geophys Res 120:9738-9747. https://doi.org/10.1002/2015J A021838

Hysell DL, Kudeki E (2004) Collisional shear instability in the equatorial F region ionosphere. J Geophys Res. https://doi.org/10.1029/2004JA010636

Hysell DL, Milla MA, Rodrigues FS, Varney RH, Huba JD (2015) Topside equatorial ionospheric density, temperature, and composition under equinox, low solar flux conditions. J Geophys Res 120:3899-3912. https://doi.org/ 10.1002/2015JA021168

leda A (2020) Ion-neutral collision frequencies for calculating ionospheric conductivity. J Geophys Res. https://doi.org/10.1029/2019JA027128

Immel TJ, England SL, Mende SB et al (2018) The ionospheric connection explorer mission: mission goals and design. Space Sci Rev. https://doi. org/10.1007/s11214-017-0449-2

Kintner PM, Ledvina BM, de Paula ER (2007) GPS and ionospheric scintillations. Space Weather 5:28163-28170. https://doi.org/10.1029/2006SW000260

Kudeki E, Bhattacharyya S (1999) Postsunset vortext in equatorial F-region plasma drifts and implications for bottomside spread-F. J Geophys Res 104:28163-28170. https://doi.org/10.1029/1998JA900111

Kudeki E, Akgiray A, Milla M, Chau JL, Hysell DL (2007) Equatorial spread-F initiation: post-sunset vortex, thermospheric winds, gravity waves. J Atmos Solar Terr Phys 69:2416-2427. https://doi.org/10.1016/j.jastp.2007.04.012

Laundal KM, Richmond AD (2017) Magnetic coordinate systems. Space Sci Rev 206:27-59. https://doi.org/10.1007/s11214-016-0275-y

Lee WK, Kil H, Kwak Y-S, Paxton LJ (2015) Morphology of the postsunset vortex in the equatorial ionospheric plasma drift. Geophys Res Lett 42:9-14

Maute, A TIEGCM V1.94 Model Description. https://www.hao.ucar.edu/model ing/tgcm/doc/description/model_description.pdf

Maute A, Richmond AD, Roble RG (2012) Sources of low-latitude ionospheric ExB drifts and their variability. J Geophys Res. https://doi.org/10.1029/ 2011JA017502
Murphy JA, Heelis RA (1986) Implications of the relationship between electromagnetic drift components at mid and low latitudes. Planet Space Sci 34:645-652. https://doi.org/10.1016/0032-0633(86)90042-5

Navarro LA, Fejer BG (2019) Storm-time thermospheric winds over peru. J Geophys Res 124:10415-10427. https://doi.org/10.1029/2019JA027256

Navarro LA, Fejer BG (2020) Storm-time coupling of equatorial nighttime F region neutral winds and plasma drifts. J Geophys Res 125:2020-028253. https://doi.org/10.1029/2020JA028253

Nayar SR, Sreehari CV (2004) Investigation of height gradient in verticalplasma drift at equatorial ionosphere using multifrequency HF doppler radar. J Geophys Res. https://doi.org/10.1029/2004JA010641

Nicolet M (1953) The collision frequency of electrons in the ionosphere. J Atmos Terr Phys 3:200-211. https://doi.org/10.1016/0021-9169(53) 90110-X

Pacheco EE, Heelis RA, Su S-Y (2011) Superrotation of the ionosphere and quiet time zonal ion drifts at low and middle latitudes observed by Republic of China Satellite-1 (ROCSAT-1). J Geophys Res. https://doi.org/ 10.1029/2011JA016786

Picone JM, Hedin AE, Drob DP, Aikin AC (2002) NRLMSISE-00 empirical model of the atmosphere: statistical comparisons and scientific issues. J Geophys Res. https://doi.org/10.1029/2002JA009430

Pingree JE, Fejer BG (1987) On the height variation of equatorial F region vertical plasma drifts. J Geophys Res 92:4763-4766. https://doi.org/10.1029/ JA092iA05p04763

Richmond AD, Fang TW, Maute A (2015) Electrodynamics of the equatorial evening ionosphere: 1. Importance of winds in different regions. J Geophys Res 120:2118-2132. https://doi.org/10.1002/2014JA020934

Rodrigues FS, Crowley G, Heelis RA, Maute A, Reynolds A (2012) On TIE-GCM simulation of the evening equatorial plasma vortex. J Geophys Res. https://doi.org/10.1029/2011JA017369

Scherliess L, Fejer BG (1999) Radar and satellite global equatorial F region vertical drift model. J Geophys Res 104:6829-6842. https://doi.org/10.1029/ 1999JA900025

Schunk RW, Nagy AF (2009) lonospheres: physics, plasma physics, and chemistry. Cambridge University Press, Cambridge

Shidler SA, Rodrigues FS (2019) On the magnitude and variability of height gradients in the equatorial F region vertical plasma drifts. J Geophys Res 124:4916-4925. https://doi.org/10.1029/2019JA026661

Shidler SA, Rodrigues FS (2021) On a simple, data-aided analytic description of the morphology of equatorial F-region zonal plasma drifts. Prog Earth Planet Sci. https://doi.org/10.1186/s40623-020-01227-w

Shidler SA, Rodrigues FS, Fejer BG, Milla MA (2019) Radar studies of heightdependent equatorial F-region vertical and zonal plasma drifts. J Geophys Res 124:2058-2071. https://doi.org/10.1029/2019JA026476

Smith JM, Rodrigues FS, de Paula ER (2015) Radar and satellite investigations of equatorial evening vertical drifts and spread F. Ann Geophys 33:14031412. https://doi.org/10.5194/angeo-33-1403-2015

Spann J, Swenson C, Durao O, Loures L, Heelis R, Bishop R, Le G, Abdu M, Krause L, Fry C, et al. (2017) The scintillation prediction observations research task (SPORT): an international science mission using a cubesat. In: Proceedings of the AIAA/Utah State University conference on small satellites

Stoneback RA, Heelis RA, Burrell AG, Coley WR, Fejer BG, Pacheco E (2011) Observations of quiet time vertical ion drift in the equatorial ionosphere during the solar minimum period of 2009. J Geophys Res. https://doi.org/ 10.1029/2011JA016712

Sultan PJ (1996) Linear theory and modeling of the Rayleigh-Taylor instability leading to the occurrence of equatorial spread F. J Geophys Res 101:26875-26891. https://doi.org/10.1029/96JA00682

Thébault E, Finlay CC, Beggan CD, Alken P, Aubert J, Barrois O, Bertrand F, Bondar T, Boness A, Brocco L, Canet E, Chambodut A, Chulliat A, Coisson P, Civet F, Du A, Fournier A, Fratter I, Gillet $\mathrm{N}$ et al (2015) International geomagnetic reference field: the 12th generation. Earth Planet Sp. https:// doi.org/10.1186/s40623-015-0228-9

Wohlwend CS (2008) Modeling the electrodynamics of the low-latitude ionosphere. Ph.D. thesis, Utah State University

\section{Publisher's Note}

Springer Nature remains neutral with regard to jurisdictional claims in published maps and institutional affiliations. 